\title{
倾斜摄影测量在农村不动产测绘中的应用研究
}

\section{Application Study on the Incline Photogrammetry in Rural Real Estate Surveying and Mapping} 尹承伟 马智慧 毕新普

\author{
Chengwei Yin Zhihui Ma Xinpu Bi
}

山东志诚地理信息技术有限公司

中国·山东 淄博 255000

Shandong Zhicheng Geographic Information

Technology Co., Ltd.,

Zibo, Shandong, 255000, China
【摘要】倾斜摄影测量技术是国际摄影测量领域近年来发展起来的一项新技术, 其通过 先进的定位、建模以及融合等技术, 将城市地物情况生成真实的三维立体模型, 以此获得 高精度的纹理信息。论文主要对倾斜摄影测量在农村不动产测绘中的应用进行详细介绍 和探讨。

【Abstract】Tilt photogrammetry is a new technology developed in the field of international photogrammetry in recent years. Through advanced positioning, modeling and fusion technology, it can generate real three-dimensional model of urban features to obtain high-precision texture information. This paper mainly introduces and discusses the application of tilt photogrammetry in rural real estate mapping.

【关键词】倾斜摄影; 农村不动产; 测绘; 应用

【Keywords 】oblique photography; rural real estate; surveying and mapping; application 【DOI】10.36012/se.v2i1.1190

\section{1 引言}

在农村不动产登记中,因农村不动产具有房型复杂、体量 大以及内部交错遮挡等特点,若使用传统测量方法 $($ RTK+全 站仪)进行实地测量的话, 会使测绘工作者野外工作量增加的 同时,工作效率也会变得非常低，而倾斜摄影技术通过将 5 台 传感器搭载在统一飞行平台上, 并从四个倾斜角度、一个垂直 角度来采集影像,然后在拍摄照片的过程中,将航高、航向、坐 标、航速以及旁向重叠等参数一同进行记录, 同时对倾斜影像 资料进行整理和分析, 从而拍摄出几组影像重叠的照片, 以此 使测绘工作者的工作量大大减少的同时，也能对农村房屋结 构进行轻松分析。

\section{2 倾斜摄影测量技术的构成}

倾斜摄影测量技术主要由三部分构成, 分别为 POS 系 统、飞行载具以及倾斜相机。其中,POS 系统指的是在航摄仪 中, 其与每组曝光影像相对应, 并使用 $X 、 Y 、 Z 、 O 、 P 、 K$ 等外方 位信息,来实时描述拍摄时的飞行姿态;飞行载具指的是对倾 斜航摄仪进行携带, 以此来完成飞行路线的航拍作业; 而倾斜 相机分为三、五、十拼等,对地面影像信息使用同步曝光的方 式进行采集 ${ }^{[1]}$ 。
3 倾斜摄影测量技术在农村不动产测绘 中的应用

\section{1 农村不动产的影像获取}

倾斜摄影测量技术是在传统测量技术的基础上，搭载了 四个不同角度的镜头, 即通过五个不同的角度对地表数据进 行全方位同步采集。而本文选取了一个面积约 $0.35 \mathrm{~km}^{2}$, 宽约 $0.44 \mathrm{~km}$, 长约 $0.8 \mathrm{~km}$ 的村子来进行测量, 然后采用倾斜摄影机 搭载四旋翼无人机,对农村不动产地物信息进行拍摄,总共飞 行 4 个架次。其中, 倾斜摄影相机参数见表 1 , 航线设计参数见 表 2 。

\section{2 农村不动产的布设像控点}

倾斜摄影测量的主要环节为布设像控点，而像控点的布 设对后期空三加密的精度以及三维模型有一定影响, 所以在 布设像控点的过程中, 要结合该地区的地物、地形、航线设计 等情况, 然后每隔 $400 \mathrm{~m}$ 布设一个像控点, 总共布设 19 个像 控点。

对农村不动产建立三维立体模型,具体如下：

(1)建立三维模型。该地区通过倾斜摄影建立三维立体模 型, 涉及 3 个关键内容, 第一, 影像预处理; 第二, 自动空三加 密, 通过立体测图技术, 对该地区内均匀分布的布设像控点匹 
表 1 倾斜相机参数

\begin{tabular}{c|c}
\hline 指标 & 参数 \\
\hline 飞行时间 $/ \mathrm{min}$ & 45 \\
\hline 起飞重量 $/ \mathrm{kg}$ & 10 \\
\hline 像素 & 120000000 \\
\hline 像元 $/ \mu \mathrm{m}$ & 3.92 \\
\hline 像幅 & $4000 \times 6000$ \\
\hline 焦距 $/ \mathrm{mm}$ & 35 \\
\hline
\end{tabular}

表 2 航线设计参数

\begin{tabular}{c|c}
\hline 项目 & 指标 \\
\hline 航线间隔 $/ \mathrm{m}$ & 30 \\
\hline 航对航高 $/ \mathrm{m}$ & 90 \\
\hline 地面分辨率 $/ \mathrm{m}$ & 0.02 \\
\hline 基线 $/ \mathrm{m}$ & 13 \\
\hline 旁向重叠 $/ \%$ & 60 \\
\hline 航向重叠 $/ \%$ & 80 \\
\hline
\end{tabular}

配高程和平面坐标; 第三,密集匹配,对多张影像上的同一个 特征点进行匹配, 并对影像之间的空间变换模型进行计算。

(2)三维测图。在农村不动产登记工作中, 最基本的要求是 对农村房屋进行逐栋测量, 即通过三维测图系统（EPS 3D Survey) 对带有实际地理位置的三维模型数据进行加载, 并结 合二三维交互采编采集一体化，对农村地物直接进行测图采 集, 不用进行房檐改正, 从而生成不动产三维模型立体测图。

(3)三维模型精度分析。测图工作在完成以后,想要对所建

\section{（上接第 53 页）}

管理工作。这一环节中, 必须对控制物体线节点、地形结构数 据进行精确的控制, 对无人机航空摄影获取的数据进行严格 审查、确认, 否则就会对立体采编精准性造成影响。

\section{4 数字地形图测绘工作}

配合全数字摄影测量工作站, 能够实现对地形图绘制的 立体数字测图, 利用无人机航空数字影像建立立体模型, 对相 关数据进行采集并形成图形文件。利用采用空三导入模式,检 查导入成果, 具体检查工作中, 是将外业检查点与空三加密使 用像片控制测量点导人测图工程中, 利用立体映射控制点进 行精读检查。在立体模型下对地形地貌、地物进行量测, 坚持 内业定位、外业定性的基本原则, 根据外业调绘内容, 实现精 确的测绘。在测图过程中,必须注意地物与地貌、地貌与地貌 之间的关系, 对于高层建筑物、树冠、阴影遮盖的地物内业可 以不测绘, 但需要利用外业进行补测。电杆等内业无法准确定 位的地物要素, 也需要利用外业进行实地补测。在数据量测完 后, 必须对地物采集精读、要素丢漏情况进行详细检查, 并进 行有效的改正。

\section{5 盲点测量、外业补测}

众所周知，现在任何先进的测绘工具都无法将全部地形
模型的精度进行验证, 就需要对数字线画图的要素精度进行 检验。即选择 16 个比较明显的地物点来当作检测点进行检测 (见表 3)。通过检测发现, 平面误差为 $0.03 \mathrm{~m}$, 高程中的误差为 $0.04 \mathrm{~m}$, 满足农村不动产登记测量的要求。

表 3 检测点误差统计

\begin{tabular}{c|c|c||c|c|c}
\hline 点号 & 平面误差 $/ \mathrm{m}$ & 高程误差 $/ \mathrm{m}$ & 点号 & 平面误差 $/ \mathrm{m}$ & 高程误差 $/ \mathrm{m}$ \\
\hline 1 & 0.01 & 0.01 & 9 & 0.06 & 0.06 \\
\hline 2 & 0.03 & 0.08 & 10 & 0.05 & 0.07 \\
\hline 3 & 0.05 & 0.09 & 11 & 0.03 & 0.03 \\
\hline 4 & 0.01 & 0.02 & 12 & 0.03 & 0.06 \\
\hline 5 & 0.04 & 0.06 & 13 & 0.03 & 0.02 \\
\hline 6 & 0.01 & 0.05 & 14 & 0.01 & 0.00 \\
\hline 7 & 0.01 & 0.08 & 15 & 0.00 & 0.03 \\
\hline 8 & 0.00 & 0.03 & 16 & 0.01 & 0.00 \\
\hline
\end{tabular}

\section{4 结语}

总的来说, 倾斜摄影测量技术作为一项新技术, 可对地物 进行全方位、多角度立体测量, 以此使测绘工作者的工作效率 得到提高的同时, 还能缩短工作时间。还有通过倾斜摄影测量 技术可对房屋的每层信息进行真实反映，直观性比较强的同 时,也能很好地反映隐蔽地区。

\section{参考文献}

[1]杨宏健,郑三君.无人机倾斜摄在农村不动产测量中的应用 $[\mathrm{J}]$. 测绘技术装备, 2017(11):81-83.

区域进行测量, 无人机航空摄影也是如此。对于测量过程中存 在的盲点,需要采用人工补测模式,对地形结构、隐蔽区域进 行测量。外业补测过程中, 必须对对比分析工作加以重视, 将 实际测量数据和无人机航摄获得数据进行对比, 保证测绘数 据的可靠准确。如果两者具有较大偏差,必须对人工测量、无 人机测量哪一个存在误差进行分析, 并进行及时修正处理, 保 证整个测绘结果精准。

\section{4 结语}

通过上述分析可知,在中国社会经济快速发展过程中,越 来越多基础设施工程投入建设中，对于地形数据要求也逐渐 提升, 传统测绘技术无法满足相关要求。无人机航空摄影测量 技术是先进的测量技术, 具有实时性、全天时、全天候的优势， 在地形图测绘中具有重要的作用。

\section{参考文献}

[1]王超.无人机航空摄影测量在地形图测绘中的应用探讨[J].城 市地理.2017,14(8):21-22.

[2]陈键锋. 无人机航空摄影测量在地形图测绘中的应用探讨 [J]. 内蒙古煤炭经济.2017,25(8):99-102. 